\title{
Valoración Crítica de la Regulación de la Legítima Defensa en el Código Penal ${ }^{1}$
}

Esp. Dimas a. Herrera Gandol ${ }^{2}$

\section{RESUMEN}

En este trabajo se valora la Legítima Defensa en sus distintas modalidades, a la luz de la doctrina y la jurisprudencia, considerándose que esta institución jurídica no está correctamente regulada en el Código Penal (CP), proponiendo al efecto las recomendaciones pertinentes. Aborda el estudio de la Legítima Defensa como institución jurídica que justifica la responsabilidad criminal de ciertos hechos típicos, valorando las diversas formas en que se materializa, y efectuar los respectivos cuestionamientos, concluyo que esta eximente, desde el punto de vista técnico-jurídico, no se encuentra correctamente regulada en nuestro Código Penal y que, a pesar de que estos defectos formales no trascienden al ámbito de la política criminal, se hace necesario realizarle las mejoras correspondientes.

Palabras clave: Legítima Defensa. Responsabilidad criminal. Política criminal.

\section{INTRODUCCIÓN}

En este trabajo se valora la Legítima Defensa en sus distintas modalidades, a la luz de la doctrina y la jurisprudencia, considerándose que esta institución jurídica no está correctamente regulada

1 Data de recebimento: 24/11/2017. Data de aceite: 19/01/2018.

2 Fiscal asistente del Fiscal General de la República. Fiscalía General de la República. E-mail: consulcubabsb@uol.com.br 
en el Código Penal (CP), proponiendo al efecto las recomendaciones pertinentes.

\section{CONCEPTO Y FUNDAMENTOS DE LA LEGÍTIMA DEFENSA}

Legítima Defensa es la reacción necesaria, proporcional y suficiente, para impedir o repeler una agresión ilegítima, inminente o actual y no provocada, contra la persona o derechos de quien se defiende, de un tercero o contra los bienes e intereses sociales, con cuya reacción se lesiona o se pone en peligro un bien jurídico, si solo de esa forma puede salvarse otro bien de más valor; entendiéndose que entre los bienes jurídicos de quien agrede y quien se defiende, merece protección jurídica los de este último.

Desde la perturbación de ánimo del defensor (Puffendorff), hasta la salvaguarda del interés preponderante (Jiménez de Asúa), se han hecho varias interpretaciones del derecho de defensa; respecto al cual expresó Montesquieu (1976: 172): “En los casos de defensa propia tengo el derecho natural de dar la muerte, porque mi vida es mía, como la vida del que me ataca es suya; lo mismo hace la guerra de un Estado, porque es justa su conservación como es legítima toda defensa".

Entre las principales teorías expuestas como fundamento, se encuentran la formulada por la escuela clásica, conforme a la cual, ante la imposibilidad de que el Estado proteja al injustamente atacado es lícito que se defienda y, la de valoración de bienes jurídicos, que plantea que no actúa antijurídicamente el que lesiona o pone en peligro un bien jurídico, si solo por ello puede salvar otro bien de más valor.

Asumiendo una posición ecléctica, la fundamentación de esta eximente puede ubicarse en el permiso concedido por el Estado al individuo para que se defienda de una agresión injusta cuando él no puede hacerlo, exigiéndole, al mismo tiempo, que el bien jurídico salvado sea de mayor valor que el lesionado, sin lo cual no tendría 
virtud esa autorización; tratándose pues de un derecho otorgado a particulares, sujeto a requisitos especiales, para ejercerlo en determinadas situaciones previamente establecidas.

\section{ANÁLISIS DE LO PRECEPTUADO EN EL ARTÍCULO 21 DEL CÓDIGO PENAL}

La legítima defensa regulada en el artículo 21 del Código Penal, admite la defensa de la propia persona y sus derechos, del tercero y de bienes e intereses sociales, exigiéndose congruencia entre sus elementos objetivos (agresión ilegítima, necesidad de defensa, proporcionalidad entre el ataque y la defensa) y subjetivos (reconocimiento de la agresión, situación de defensa y finalidad defensiva), siendo preciso que la acción defensiva (resultado valioso), esté impregnada del ánimo de defensa (valor de acción).

Artículo 21.1. "Está exento de responsabilidad penal el que obra en legítima defensa de su persona o derechos": La situación de legítima defensa exige de una conducta que atente contra una persona o sus derechos (la agresión) y una reacción del agredido (la defensa), procediendo la defensa de la vida, la integridad corporal, la libertad, el domicilio, la propiedad y todos los que puedan ser objeto de una agresión ilegítima, pero mientras no se acrediten los elementos fácticos de la causa de justificación, el hecho será típico y antijurídico. La Sentencia No. 232 del TS de 6 de Septiembre de 1940, expresó, "Toda causa justificación debe quedar plenamente probada, sin necesidad de realizar inferencias o deducciones de las que aquella puedan derivarse".

Artículo 21.2. "Obra en legítima defensa el que impide o repele una agresión ilegítima, inminente o actual y no provocada": La agresión, gramatical y jurídicamente, es un hecho material de acometimiento, que pone en peligro actual o inminente intereses jurídicos; considerándose ilegítima cuando el acto de fuerza se realiza sin derecho 
y sin razón; siendo impropia la defensa ante conductas típicas no antijurídicas, el ataque de inimputables y de quien obra por miedo insuperable, por ser actos lícitos o no conscientes y voluntarios. De igual modo, la riña excluye la legítima defensa por ser todos agresores y agredidos.

La legítima defensa puede ser preventiva, si se dirige a impedir una agresión inminente, que amenaza con producirse de modo inconfundible, o represiva, si repele la actual, la que acontece. La situación de defensa se extiende desde que es apreciada la amenaza inmediata para el bien jurídico, hasta que haya cesado la actividad lesiva o la posibilidad de retrotraer o neutralizar sus efectos. La agresión pasada legitimaría la venganza y la futura salvaguardaría el miedo. El estado de agresión inmediata no puede depender del proceso mental interno de la víctima que se siente en peligro de ataque, difícil de probar, pero tampoco debe supeditarse a su probabilidad matemática, siendo más fácil para su apreciación la agresión actual, por ser la que se está desarrollando.

La provocación es la acción intencional, dirigida por quien después se defiende hacia el futuro agresor, suponiendo una relación de causalidad entre provocación y agresión, debiendo ser la causa adecuada o necesaria de la última, porque si ésta, o su magnitud, no concuerdan con la primera, no puede eliminar el fundamento de la legítima defensa. El provocador, en determinados casos y circunstancias, tiene derecho a defenderse ante una respuesta desproporcionada, porque esa desproporción en el ataque tiene efecto mutilante sobre la provocación que lo origina. Piénsese en un sujeto que ante una ofensa verbal responde disparando un arma de fuego para matar a quien le ofende.

Para Jiménez de Asúa la provocación vicia en su causa la legítima defensa, mientras que Silvela expresó, "Es justo decir que el provocador no puede ser obligado a dejarse matar o condenarlo por haber cometido un delito al defenderse de quien reaccionó ante su 
provocación" (citado por Hernández de Armas, Nicasio, 1975: 82); refiriendo el TSP en sentencia No. 681 de 15 de mayo de 1974, “Obra en legítima defensa de su vida el acusado que toma una pistola y se dispone a repeler una agresión al ser sorprendido de noche, en convivencia con la esposa y en el domicilio conyugal del que resultó lesionado, cuando éste se introduce súbitamente en el referido domicilio con una pistola en la mano; pues necesariamente se tuvo que representar que era objeto de una agresión mortal contra su vida, lo que no justifica la responsabilidad ética de su conducta reprochable".

La provocación que invalida la legítima defensa, debe ser la que fundadamente induzca u obligue a la agresión, según las circunstancias en que se ejecuta y la persona a quien se dirige, infiriéndose que se ha buscado, que está dirigida a ello, considerando más acertada la redacción del Código de Defensa Social (CDS) que expresaba "no provocada ni buscada de propósito", porque la del CP "y no provocada", de la forma que se expresa, absolutiza que toda provocación invalida la justificación, sin distinguir, cuando la doctrina y la jurisprudencia afirman lo contrario. Según la sentencia del TS No. 373 de 18 de diciembre de 1941, la agresión solo deja de ser injusta cuando ha sido provocada con el propósito de crear una situación de defensa.

Lo correcto sería "y no provocada intencionalmente", indicando con exactitud que la provocación que invalida la actuación en legítima defensa es la que tiene el propósito de colocarse en ese estado, de forma directa o eventual, precisando una relación causal entre la provocación y la agresión, para excluir, como sinónimo de provocación los actos no son idóneos o suficientes para desencadenar una determinada agresión, librando al sujeto de soportar la desproporción, pues solo quien intencionalmente provoque la agresión que se produce, debe ser privado de la posibilidad de defenderse legítimamente.

Artículo 21.2.a. "Necesidad objetiva de la defensa": Su apreciación exige la inexistencia de otra vía para conjurar la agresión que no sea mediante el despliegue de la conducta típica, pues la simple 
suposición de una agresión no permite que la eximente cobre vida, sobre lo cual la sentencia No. 3692 de 9 de diciembre de 1988 del TSP, expuso, "Para ser acreedor de la eximente de legítima defensa no basta que exista una agresión ilegítima y no provocada por el que se defiende, sino que tiene que existir la necesidad objetiva de esa defensa".

Pero no puede pedirse a los ciudadanos, jurídicamente, huir del enfrentamiento para evitar la agresión, lo que se ha descartado en la jurisprudencia española (sentencias del TS de 3 de abril de 1976, 23 de marzo de 1988 y 30 de octubre de 1990). De la misma forma, la posibilidad eventual de recibir auxilio no es motivo para desestimar la legítima defensa.

Luzón Peña considera que no es posible alegar legítima defensa cuando se reciben los efectos de una tentativa inidónea o delito imposible por cuanto no existe antijuricidad, toda vez que no hay afectación de bienes jurídicos, mientras que otros autores opinan que no puede negársele a la víctima de un delito imposible que se defienda de quien intenta matarlo aunque los medios no sean idóneos.

Imaginemos a un sujeto que se ve frente a su mortal enemigo, el cual, empuñando un arma de fuego sin proyectiles, hace un ademán para dispararle. Es obvio que puede y debe defenderse, no siendo exigible, en esas circunstancias, verificar la idoneidad del medio empleado para la agresión, pero también es cierto que no había necesidad objetiva de defenderse, estando entonces frente a una legítima defensa putativa, la que tendrá amparo legal en la eximente del error, porque éste, ciertamente, era invencible.

Artículo 21.2.b. "Proporcionalidad entre la agresión y la defensa, determinada en cada caso con criterios razonables, según las circunstancias de personas, medios, tiempo y lugar": Se estipula la proporcionalidad entre la agresión y la defensa, no entre medios de ataque y defensa como establecía el CDS, pues son las circunstancias de personas, medios, tiempo y lugar, apreciadas racionalmente, las 
que determinarán si esa proporcionalidad existe.

El hombre que sufre una agresión inesperada e injusta tiene derecho a defenderse con las armas que disponga, cumpliendo el principio de ponderación de bienes. La desproporción del medio empleado para defenderse implica escoger conscientemente un medio superior al necesario, habiendo disponible otros también eficientes pero menos drásticos. En la sentencia No. 233 de 28 de julio de 1942, el TS explicó, "en la estimación de la racionalidad del medio empleado para repeler y evitar una agresión ilegítima, no hay ni puede haber reglas morales ni jurídicas fijas ni precisas, dada la multiplicidad de casos y la diversidad de las circunstancias que pueden concurrir".

Artículo 21.3. "Está igualmente exento de responsabilidad penal el que defiende a un tercero en las condiciones y con los requisitos exigidos en el apartado 2, aunque la agresión haya sido provocada, si el defensor no participó en la provocación": Se exigen los requisitos de la defensa propia, salvo la falta de provocación, admitiendo la posibilidad de que haya existido por parte del defendido, si el defensor no participó en la provocación; con lo que se abandonan aciertos del derogado CDS, restringiéndose además la defensa del tercero a su persona exclusivamente, obviando sus derechos.

No hay dudas en cuanto a la configuración de la eximente cuando se defiende a un tercero objeto de una agresión ilegítima, inminente o actual y no provocada por él, cumpliéndose los requisitos de necesidad objetiva de la defensa y proporcionalidad entre el ataque y la defensa, pues son los mismos que se tienen en cuenta en la legítima defensa propia, con la diferencia que el defensor no es la persona que recibe el ataque. La confusión comienza al autorizarse la defensa de un tercero provocador, vulnerando con ello, o desconociendo, los principios, condiciones, requisitos y fundamentos sobre los que erige esta institución.

Quien provoca una agresión, y ya se ha explicado a que provocación nos referimos, no debe esperar que el derecho ampare su 
defensa, porque la falta de provocación es una exigencia para la corporificación de la eximente, resultando obvio que la falta del requisito afecta al provocador y al defensor, por recaer sobre elementos fácticos de la causa de justificación, llamando la atención que si el defensor participó o conoció de la provocación no se configura la eximente, pero si desconocía que la persona a quien defiende era el provocador, lo ampara la justificante; de modo que la legalidad de su actuación no es por la concurrencia objetiva de los elementos que apuntalan la institución, sino por la falta de coincidencia entre la realidad de los hechos y su representación, es decir, el desconocimiento de que la agresión había sido provocada; haciendo recaer la causa de justificación sobre el autor, ignorando su carácter objetivo.

Admitir la legítima defensa de un tercero provocador, existiendo relación causal entre la provocación y la agresión, es sin duda alguna una metáfora jurídica. En todo caso pudiera gravitar sobre el actuante la inculpabilidad por error o la justificación por cumplimiento de un deber, según el caso.

Otro aspecto cuestionable, es el haber eliminado la posibilidad de defender legítimamente otros derechos que no sean los de la persona del tercero, como el CDS, pues nada niega que un derecho, como el de la propiedad, pueda ser objeto de una agresión ilegítima, inminente o actual y no provocada, y exista además necesidad objetiva de su defensa, faltando únicamente el amparo legal para actuar.

Artículo 21.4. "Asimismo, obra en legítima defensa el que impide o repele en forma adecuada un peligro o un daño inminente o actual a la paz pública o a los bienes e intereses sociales o del Estado": Se trata de la defensa de bienes sociales, exigiéndose que la defensa sea la adecuada para impedir o repeler un peligro o un daño inminente o actual, debiendo corresponder la defensa a la entidad del daño o del peligro; considerándose por algunos autores como una innovación del CP; criterio que no comparto, por estimar que la formulación de este precepto es, por un lado, una redundancia jurídica y, por otro, un desacierto técnico, asistiéndole razón a Binding cuando sostenía que 
la defensa del Estado no era una legítima defensa, sino un ejercicio de derecho autónomo.

En cualquier Estado, el cumplimiento de los deberes fundamentales reviste importancia trascendental. Nuestra Constitución, en su artículo 64, establece que es deber de cada uno cuidar la propiedad pública y social, consagrando en el artículo 65 que la defensa de la Patria Socialista es el más grande honor y deber supremo de cada cubano; concibiéndose como tal la defensa de todos y cada uno de los bienes e intereses sociales regulados en la propia carta magna, lo que supone, desde luego, la defensa contra cualquier ataque que ponga en peligro esos bienes o intereses.

En el artículo 66 se establece que el cumplimiento estricto de la Constitución y las leyes es deber inexcusable de todos; debiendo entenderse entonces que la defensa de los bienes o intereses sociales y de la paz pública, es un deber de la colectividad ante conductas que impliquen peligro o daño para ellos; por eso, quien impide o repele en forma adecuada un peligro o un daño inminente o actual a la paz pública o a los bienes o intereses sociales o del Estado, está exento de responsabilidad penal en virtud del cumplimiento de un deber impuesto a cada ciudadano por la ley suprema, pero no por legítima.

Es fácil advertir además que no se exige el requisito de la agresión ilegítima, aludiendo solamente al peligro o daño, inminente o actual, que debe repelerse o impedirse en forma adecuada; lo que convierte este precepto en una copia deformada del estado de necesidad.

Artículo 21.5. "Si el que repele la agresión se excede en los límites de la legítima defensa, $y$, especialmente, si usa un medio de defensa desproporcionado en relación con el peligro suscitado por el ataque, el Tribunal puede rebajar la sanción hasta en dos tercios de su límite mínimo, y si se ha cometido este exceso a causa de la excitación o la emoción violenta provocada por la agresión, puede aun prescindir de imponerle sanción alguna": No admite dudas la posible rebaja de sanción por exceso en la defensa y desproporcionalidad en el medio, al sustentarse en elementos fácticos; se objeta la inclusión del exceso 
a causa de excitación o emoción violenta provocada por la agresión, por abandonarse el análisis de requisitos objetivos de la justificante, que actúa sobre el hecho, para analizar la inculpabilidad del autor, como elemento fundamental, lo que pudiera hacerse, en los casos concretos, en base al error, el miedo insuperable, trastorno mental transitorio o facultad sustancialmente disminuida para comprender el alcance de la acción y dirigir la conducta; es decir, por inculpabilidad y por inimputabilidad.

Asimismo, debiera acogerse como modalidad de la legítima defensa incompleta el caso del sujeto que impide o repele una agresión ilegítima que provocó, si la agresión es desproporcionada en relación con la provocación, pues, como se expuso, en muchos casos la provocación no elimina la ilicitud de la agresión.

\section{PROPUESTA DE FORMULACIÓN DEL ARTÍCULO 21 DEL CÓDIGO PENAL}

De conformidad con los criterios vertidos, la formulación correcta del Artículo 21 del Código Penal debiera ser la que a continuación se expone.

Artículo 21.1. Está exento de responsabilidad penal el que obra en legítima defensa de su persona o derechos

2. Obra en legítima defensa el que impide o repele una agresión ilegítima, inminente o actual y no provocada intencionalmente, si concurren, además, los requisitos siguientes:

a) Necesidad objetiva de la defensa

b) Proporcionalidad entre la agresión y la defensa, determinada en cada caso con criterios razonables, según las circunstancias de personas, medios, tiempo y lugar

3. Está igualmente exento de responsabilidad penal el que defiende la persona o los derechos de un tercero en las condiciones y con los requisitos exigidos en el apartado 2 .

4. Si el que repele la agresión se excede en los límites de la legítima defensa, $y$, especialmente, si usa un medio de defensa despropor- 
cionado en relación con el peligro suscitado por el ataque o si, en su caso, la agresión que repele es desproporcionada respecto a la provocación que la causó, el Tribunal puede rebajar la sanción hasta en dos tercios de su límite mínimo o exonerar de responsabilidad cuando las circunstancias del hecho lo justifiquen.

\section{CONCLUSIONES}

Al abordar el estudio de la Legítima Defensa como institución jurídica que justifica la responsabilidad criminal de ciertos hechos típicos, valorando las diversas formas en que se materializa, y efectuar los respectivos cuestionamientos, concluyo que esta eximente, desde el punto de vista técnico-jurídico, no se encuentra correctamente regulada en nuestro Código Penal y que, a pesar de que estos defectos formales no trascienden al ámbito de la política criminal, se hace necesario realizarle las mejoras correspondientes.

\section{RESUMO}

Este trabalho se valora a legítima defesa em suas distintas modalidades, à luz da doutrina e a jurisprudência, considerando que esta instituição jurídica não está corretamente regulada no Código Penal (CP), propondo ao efeito as recomendações pertinentes. Aborda o estudo da legítima defesa como instituição jurídica que justifica a responsabilidade criminal de certos fatos típicos, valorando as diversas formas em que se materializa, e efetuar os respectivos questionamentos, concluo que esta examine, desde o ponto de vista técnico-jurídico, não se encontra corretamente regulada no nosso Código Penal e que, apesar de que estes defeitos formais não transcendem ao âmbito da política criminal, se faz necessário realizar as melhoras correspondentes.

Palavras-chave: Legítima Defesa. Responsabilidade criminal. Política criminal. 


\section{REFERENCIAS}

Álvarez Tabío, Fernando. 1989. Comentarios a la Constitución Socialista. Editorial de Ciencias Sociales, La Habana, Cuba.

Casasús, Juan J.E. 1950. Código de Defensa Social y Derecho Penal Complementario. Segunda Edición, Tomo I. Editorial Molina y Compañía, La Habana, Cuba.

Código Penal, Ley No. 62 del 29 de diciembre de 1987.

Cuello Calón, Eugenio. 1982. Derecho Penal. Parte Especial, Tomo II, Decimocuarta Edición. Bosch Casa Editorial S.A., Barcelona, España.

Chirino, Alfredo y Salas, Ricardo. 1993. La Legítima Defensa. Alcance y Límites Dogmáticos y Jurisprudenciales. Investigaciones Jurídicas S.A., Costa Rica.

Hernández de Arma, Nicasio. "Apuntes Para un Estudio de la Legítima Defensa". Revista Cubana de Derecho No. 9, Año IV, Enero-Junio 1975. La Habana, Cuba.

Jiménez de Asúa, Luis. 1950. Tratado de Derecho Penal. Tomo I-II. Edit. Losada S.A., Buenos Aires, Argentina. Masa y Rodríguez, Emilio. 1943. La Legítima Defensa en la Jurisprudencia Cubana. Primera Edición. Jesús Montero Editor, La Habana, Cuba.

Montesquieu. 1976. El Espíritu de las Leyes. Editorial C. Sociales, La Habana, Cuba.

Quirós Pírez, Renén. 1999. Manual de Derecho Penal. Tomo I. Editorial Félix Varela, La Habana, Cuba.

Rusconi, Maximiliano Adolfo. S/A. La Justificación en el Derecho Penal, Algunos Problemas Actuales. Editorial

AD-HOC S.R.L., Buenos Aires, Argentina.

Sainz Cantero, José A. 1984. "La Legítima Defensa y el Estado de Necesidad". Revista de Divulgación Jurídica MINJUS No. 1, La Habana, Cuba.

Zaffaroni, Eugenio Raúl. 1988. Tratado de Derecho Penal. Editorial Cárdenas, México. 